\title{
Communication
}

\section{In Ovarian Cancer Multicellular Spheroids, Platelet Releasate Promotes Growth, Expansion of ALDH+ and CD133+ Cancer Stem Cells, and Protection against the Cytotoxic Effects of Cisplatin, Carboplatin and Paclitaxel}

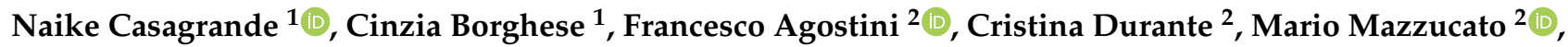 \\ Alfonso Colombatti ${ }^{1}$ and Donatella Aldinucci ${ }^{1, *(1)}$ \\ 1 Molecular Oncology Unit, Centro di Riferimento Oncologico di Aviano (CRO), IRCCS, 33081 Aviano, Italy; \\ naike.casagrande@cro.it (N.C.); cpborghese@cro.it (C.B.); acolombatti@cro.it (A.C.) \\ 2 Stem Cell Unit, Centro di Riferimento Oncologico di Aviano (CRO) IRCCS, 33081 Aviano, Italy; \\ fagostini@cro.it (F.A.); cdurante@cro.it (C.D.); mmazzucato@cro.it (M.M.) \\ * Correspondence: daldinucci@cro.it
}

Citation: Casagrande, N.; Borghese,

C.; Agostini, F.; Durante, C.;

Mazzucato, M.; Colombatti, A.;

Aldinucci, D. In Ovarian Cancer Multicellular Spheroids, Platelet

Releasate Promotes Growth,

Expansion of ALDH+ and CD133+

Cancer Stem Cells, and Protection against the Cytotoxic Effects of Cisplatin, Carboplatin and Paclitaxel. Int. J. Mol. Sci. 2021, 22, 3019.

https://doi.org/10.3390/

ijms22063019

Academic Editor: Valeria Gasperi

Received: 17 February 2021

Accepted: 12 March 2021

Published: 16 March 2021

Publisher's Note: MDPI stays neutral with regard to jurisdictional claims in published maps and institutional affiliations.

Copyright: (c) 2021 by the authors. Licensee MDPI, Basel, Switzerland. This article is an open access article distributed under the terms and conditions of the Creative Commons Attribution (CC BY) license (https:/ / creativecommons.org/licenses/by/ $4.0 /)$.
Abstract: A high platelet count is associated with a poor prognosis in ovarian cancer (OvCa). Despite good clinical responses with platinating agents in combination with taxanes, numerous OvCa patients relapse due to chemotherapy resistance. Here, we report that treatment of OvCa cells A2780, OVCAR5 and MDAH with releasate from activated platelets (PR) promoted multicellular tumor spheroid (MCTS) formation. These OvCa-MCTSs had increased percentages of CD133+ and aldehyde dehydrogenase (ALDH)+ cells, bona fide markers of OvCa cancer stem cells (CSCs). PR increased OVCAR5- and MDAH-MCTS viability and decreased the cytotoxic and pro-apoptotic effects of paclitaxel, cisplatin and carboplatin. PR increased the volume of spontaneously formed OVCAR8-MCTSs and counteracted their size reduction due to cisplatin, carboplatin and paclitaxel treatment. PR promoted the survival of ALDH+ and CD133+ OvCa cells during cisplatin, carboplatin and paclitaxel treatment. In conclusion, molecules and growth factors released by activated platelets (EGF, PDGF, TGF- $\beta$, IGF and CCL5) may protect tumor cells from chemotherapy by promoting the expansion of $\mathrm{ALDH}+$ and $\mathrm{CD} 133+\mathrm{OvCa}-\mathrm{CSC}$, favoring drug resistance and tumor relapse.

Keywords: platelet releasate; ovarian cancer stem cells; ovarian cancer spheroids; anticancer therapy; drug resistance; cisplatin; carboplatin; paclitaxel

\section{Introduction}

An increased platelet count is correlated with poor disease-free survival (DFS) and overall survival in various cancers [1-3], including ovarian cancer (OvCa) [4-7]. Indeed, platelets and molecules secreted by platelets affect tumor growth, metastasis and anticancer drug activity [8-12]. In turn, tumor cells can stimulate platelet production and activation, leading to an abnormally increased number of platelets in the blood (thrombocytosis) and to the release of growth factors, cytokines, chemokines and vesicular signals, collectively termed "platelet releasate" (PR) [12-14]. PR contains vascular endothelial growth factor (VEGF) and fibroblast growth factor (FGF), which stimulate angiogenesis; TGF-beta, which promotes tumor growth; and CCL5, which is involved in cancer progression and cisplatin resistance [15-17]. Preclinical and clinical studies suggest the involvement of platelets and their products in OvCa progression $[14,15,18,19]$. In patients with OvCa, paraneoplastic trombocytosis [4] and a high platelet count were negatively correlated with the response to taxane-based therapies $[5,7]$ and abundant platelets have also been found in tumor tissues and in ascitic fluids $[6,20]$. The co-culture of platelets with $\mathrm{OvCa}$ cells increased tridimensional multicellular tumor spheroid (MCTS) formation, with the expression of metastasis-initiating cell markers and migration [20], which was inhibited 
by aspirin [21]. PR increased the proliferation and protected OvCa cells from apoptosis (in a two-dimensional model) through a mechanism that did not require a direct cell-cell contact $[5,22]$. Similarly, PR increased tumor growth and decreased docetaxel activity in OvCa xenograft models [5].

Considering this evidence, our hypothesis was that growth factors secreted by platelets, by promoting the expansion of the putative drug-resistant CD133+ and ALDH+ OvCa cancer stem cells (CSCs), could decrease the anticancer activity of paclitaxel (PTX), cisplatin (CDDP) and carboplatin (CBDCA), the standard postoperative chemotherapy medications [23] for $\mathrm{OvCa}$, and could thus justify the poor prognosis observed in patients with high platelet counts [11].

Using drug-resistant three-dimensional multicellular OvCa MCTSs [24-26], we studied the effects of molecules released by physiological activated platelets (PR) [27-29] on OvCa-CSC expansion and PTX, CDDP and CBDCA treatments.

Here, we show that PR increased OvCa-MCTS formation, as well as growth and the expression of the CSCs markers ALDH and CD133, whereas it decreased CDDP, CBDCA and PTX cytotoxicity, maintaining high levels of CSC markers.

\section{Results and Discussion}

OvCa patients are responsive to chemotherapy (cisplatin, carboplatin and docetaxel) at first; however, the main obstacles for successful chemotherapy are represented by drug toxicity and drug resistance [23]. Drug resistance can be intrinsic, acquired or achieved by the aggregation of tumor cells as spheroids or heterospheroids (the interaction of tumor cells with normal cells). These aggregates of tumor cells, called multicellular tumor spheroids (MCTSs) are less sensitive to anticancer drugs and are capable of disseminating in the peritoneum to form metastasis [30-32], and are found in malignant ascites formed in late-stage OvCa patients with peritoneal carcinomatosis. Subpopulations of these tumor cells exhibit CSC features. They self-renew, grow as MCTSs, express CD133 and ALDH, and possess enhanced resistance to chemotherapy [33-35]. Malignant ascites can contain platelets, free or associated with OvCa-MCTSs [20] and the 3D cell culture model is now considered to be more representative of the tumor architecture and is more often used to study drug activity compared to the 2D model inOvCa [36]. Platelets act as a reservoir of a complex mixture of soluble factors and cellular components, which provide a proinflammatory and tumor-promoting microenvironment for tumor cells [3].

Our results demonstrate that PR [27], used as a source of cytokines secreted by activated platelets, increased OvCa-MCTS formation, growth and the expression of the CSC markers ALDH and CD133. Moreover, it counteracted the cytotoxic effects of CDDP, CBDCA and PTX, maintaining high levels of CSC markers after drug treatment.

First, under non-adherent conditions, PR induced the self-aggregation of OvCa cells in MCTSs (Figure 1A,B). Representative phase-contrast photomicrographs of the dosedependent formation of MTCSs by OVCAR5, A2780 and MDAH treated with PR are shown in Figure 1B.

These results suggest that not only the direct cell contact with platelets [20], but also with molecules released by platelets, may promote the aggregation of OvCa cells as MCTSs in ascitic fluids.

Then, we evaluated the CSC markers ALDH and CD133 by means of flow cytometry in OvCa cells cultured with and without PR (10\%) (under non-adherent conditions) and found that PR at $10 \% v / v$ significantly increased the percentage of ALDH+ (Figure 2A,B) and CD133+ cells (Figure 2C,D). Representative flow cytometric dot-plots showing ALDH enzymatic activity and CD133 expression by OvCa cells treated or not treated with PR are shown in Figures 2B and 2D, respectively. 
A

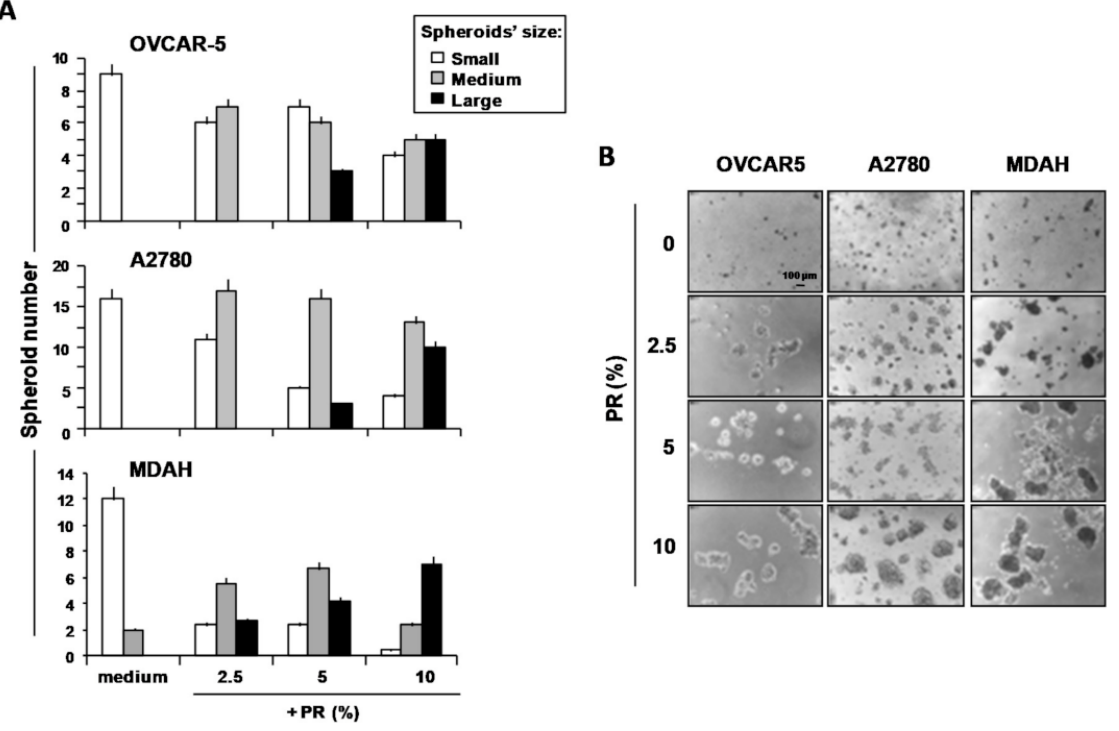

Figure 1. Human platelet releasate (PR) increased spheroid formation in OVCAR5, A2780 and MDAH cells. Cells were cultured on poly-HEMA-coated plates with or without increasing concentrations of PR pools. (A) After 5 days, images were captured using an inverted microscope and spheroids were counted (number of cells/spheroid: 2-5 = small; 6-20 = medium; $>20=$ large). Data are expressed as mean \pm SEM of three replicates with three different PR pools. (B) Representative phasecontrast photomicrographs (original magnification $4 \times$ ) showing the formation of ovarian cancer (OvCa) cell multicellular tumor spheroids (MCTSs) in the presence of various PR concentrations.

A

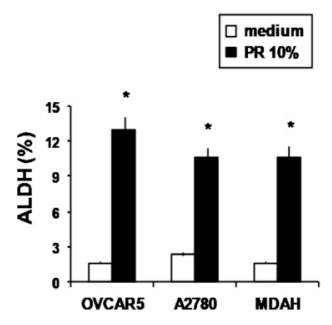

B

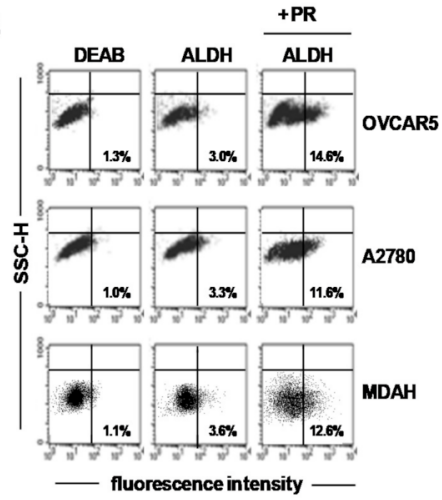

C

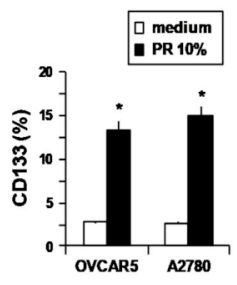

D

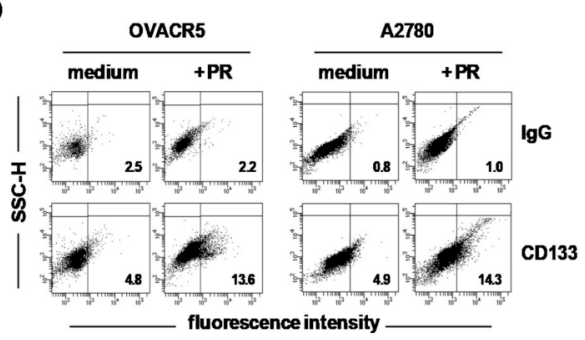

Figure 2. Human PR increased ALDH activity and CD133 expression in OvCa cells. (A-D) OvCa cells treated for 5 days with or without $10 \%$ PR were dissociated into single-cell suspensions by trypsinization, and then ALDH activity and CD133 expression were evaluated by means of flow cytometry. Results represent the percentage of ALDH-positive (A) and CD133-positive (C) cells. Data are expressed as mean \pm SEM of three replicates with three different PR pools. ${ }^{*} p<0.01$ (untreated vs. PR treated cells). (B) Representative flow cytometric dot-plots showing ALDH-positive cells. The ALDH inhibitor diethylaminobenzaldehyde (DEAB) was used as a negative control. (D) Representative flow cytometric histograms showing CD133 expression. 
These results, showing that PR induced the formation of MCTSs and increased both ALDH and CD133 expression suggest that cytokines secreted by platelets, including TGF $\beta$ (Supplemental Figure S1), by favoring the expansion of the drug-resistant cancer stem cells, could decrease the anticancer activity of chemotherapy agents.

At present, the standard treatment for OvCa involves tumor debulking with taxanes, CDDP or CBDCA [37]. These drugs are very effective for OvCa treatment but their toxicity and intrinsic and acquired drug resistance limit their efficacy. To determine the potential protective effects against chemotherapy of PR pre-treatment, we evaluated the cytotoxic effects of CDDP, CBDCA and PTX and the expression of ALDH and CD133 CSC markers in MCTSs obtained through the cultivation of OvCa cells with PR.

Both OVCAR5 and MDAH cells were cultured with PR $(10 \% v / v)$ for 5 days (Figure 1A) to allow MTCS formation, then they were treated with CDDP, CBDCA and PTX for $72 \mathrm{~h}$.

Treatment of OVCAR5 (Figure 3A) and MDAH (Figure 3B) cells with PR significantly increased the number of viable cells (about 2-fold) and partially counteracted growth inhibition by CDDP, CBDCA and PTX in both cell lines (Figure 3A,B).

A

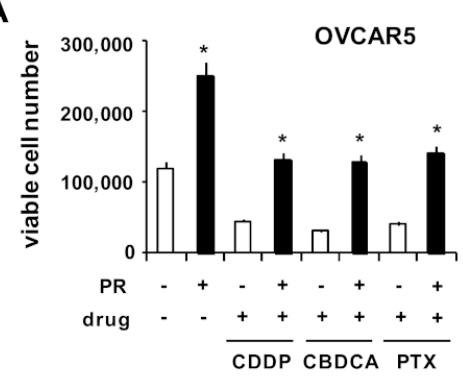

B

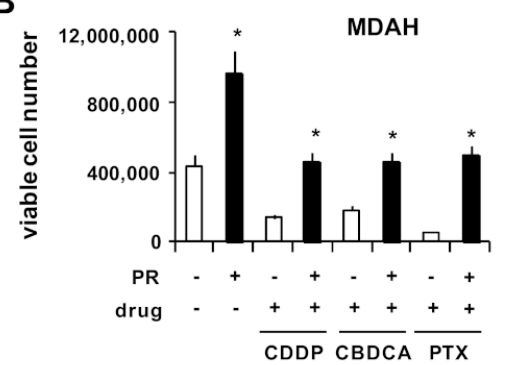

Figure 3. PR increased OvCa cell viability and survival after drug treatment. OvCa cells were cultured for 5 days with PR (10\%) on poly-HEMA-coated wells to form spheroids. Then, cells were treated with CDDP, CBDCA and PTX. After $72 \mathrm{~h}$ of drug treatment, OvCa spheroids were dissociated into single-cell suspensions by trypsinization and the number of viable cells was evaluated. Histograms showing OVCAR5 (A) and MDAH (B) viable cell numbers evaluated by the trypan blue dye exclusion assay. ${ }^{*} p<0.01$ (untreated vs. PR-treated cells).

Accordingly, the treatment with PR decreased the pro-apoptotic effects of all drugs (Figure 4). In fact, although drugs increased the percentage of Annexin-V+ (apoptosis) and Annexin-V/PI+ (late apoptosis) in OVCAR5 (Figure 4A,B) and MDAH cells (Figure 4C,D), these effects were partially reduced by PR. Representative flow cytometric dot-plots are shown in Figure 4B,D.

PR-mediated cell growth and drug resistance were also evaluated in OVCAR8 cells, which were capable of spontaneously forming compact single MCTSs. As shown in Figure 5A, PR increased OVCAR8 spheroid growth in a dose-dependent manner, as evaluated by spheroid volume, and decreased the growth inhibition induced by CDDP, CBDCA and PTX in a dose-dependent manner (Figure 5A). Representative phase-contrast photomicrographs showing the effects of PR on drug activity in OVCAR8 MCTSs are reported in Figure 5B. 
A

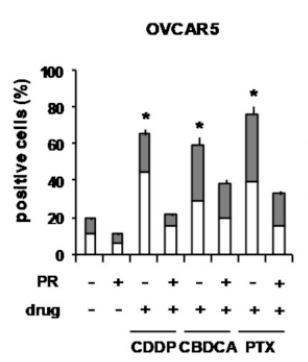

C

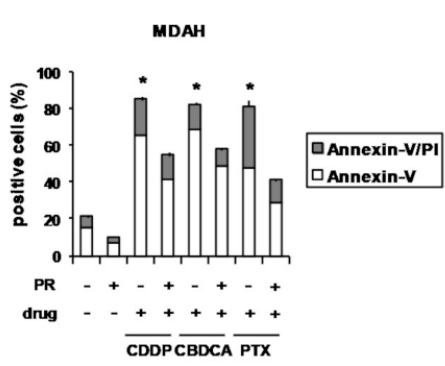

B

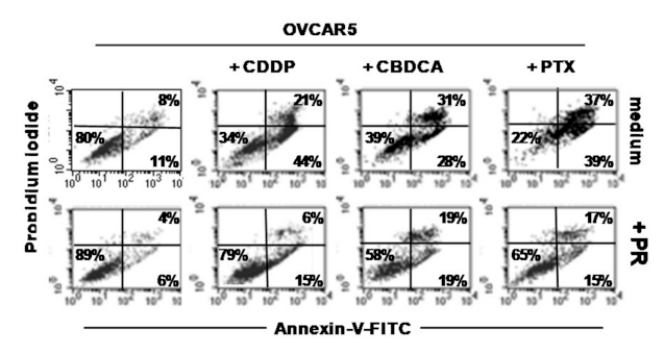

D

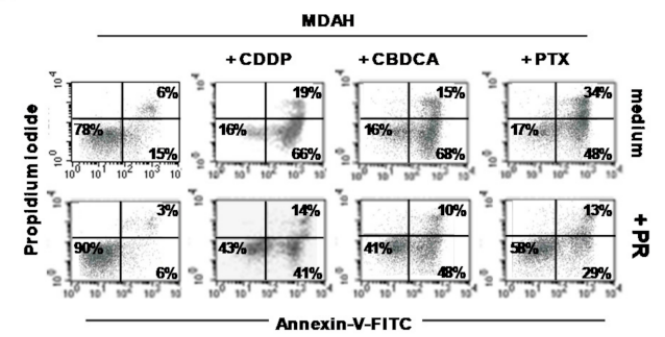

Figure 4. PR reduced the pro-apoptotic effects of CDDP, CBDCA and PTX in PR-OvCa spheroids. OVCAR5 and MDAH cells were cultured for 5 days with PR (10\%) in poly-HEMA-coated wells to form spheroids. Then, cells were treated with CDDP, CBDCA and PTX. After $72 \mathrm{~h}$, OvCa spheroids were dissociated into single-cell suspensions by means of trypsinization and stained with Annexin-VFITC and PI. (A,C) Histograms showing the percentage of Annexin-V- and Annexin-V/PI-positive cells (B,D) Representative flow cytometric dot-plots showing the percentage of Annexin-V-, AnnexinV/PI- and PI-positive cells. ${ }^{*} p<0.01$ (untreated vs. PR-treated cells).

A

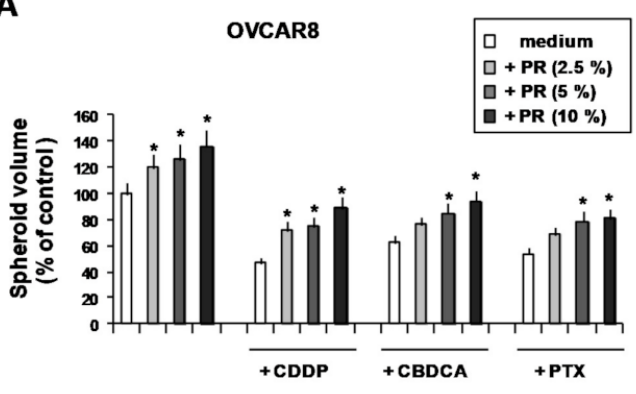

B

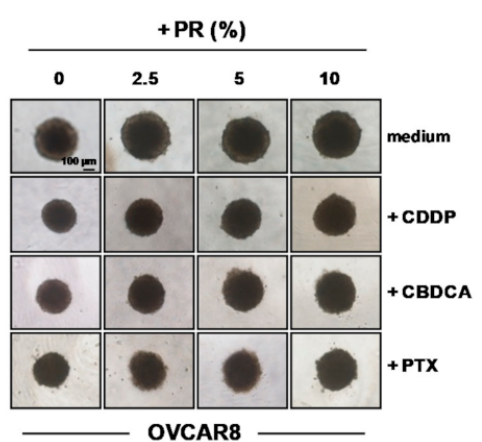

Figure 5. PR increased the volume of OVCAR8 spontaneously-formed single spheroids and decreased their growth inhibition due to CDDP, CBDCA and PTX. Three-day-old OVCAR8 spheroids were treated with increasing concentrations of PR for 24 hours, then for an additional 3 days with CDDP, CBDCA and PTX. (A) Responses were evaluated by measuring the volume of at least three spheroids. (B) Representative phase-contrast microphotographs showing the volume of OVCA8 spheroids treated with PR, drugs and the combination drugs/PR. Data are expressed as mean $\pm \mathrm{SD}$ of three replicates with three different $\mathrm{PR}$ pools and represent the percentage with respect to control medium. * $p<0.05$ (untreated vs. PR-treated cells).

In OvCa, chemotherapy resistance is often associated with high ALDH enzymatic activity [33], a functional regulator [38] and a marker of stemness in many cancer models [39]. ALDH, in combination with CD133, represents a robust marker for OvCa-CSCs [40-42]. OvCa-CSCs are thought to contribute to disease recurrence and chemo-resistance; thus, it is challenging to clarify the mechanism leading to their expansion and survival during chemotherapy. We hypothesized that PR could counteract drug activity by allowing the survival of the resistant OvCa-CSCs (ALDH+ and CD133+). We cultured OvCa cells under non-adherent conditions with and without PR for 5 days to generate MCTSs. Then, 
MCTSs were treated for three more days with a cytotoxic dose of CDDP, CBDCA and PTX (Table S2). Finally, CD133 expression and ALDH enzymatic activity were evaluated by means of flow cytometry. PR increased the percentage of ALDH+ cells, which was maintained in OVCAR5 (Figure 6A) and MDAH cells (Figure 6B) after treatment with drugs and PR. PR, by increasing the number of viable cells, together with the percentage of ALDH+ cells, also strongly increased the total number of ALDH+ cells in drug-treated OVCAR5 (Figure 6C) and MDAH cells (Figure 6D), with respect to untreated cells. Indeed, $\mathrm{ALDH}^{\text {high }}$ OvCa CSCs display an enhanced ability to form spheroids, generate metastasis and resist apoptosis and drug activity $[35,43]$. ALDH ${ }^{\text {high }} \mathrm{OvCa}$ CSCs are enriched in residual xenografts after platinum therapy and are 100-fold higher in OvCa cells selected for taxane-resistance in vitro [43]. Accordingly, ALDH expression increases in residual tumors after the first round of chemotherapy, compared to tumors from untreated patients [43].

A

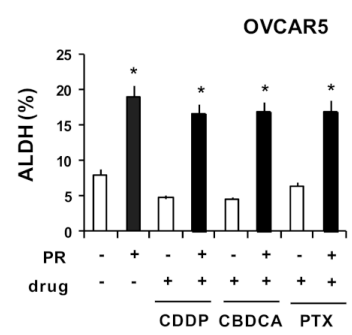

C

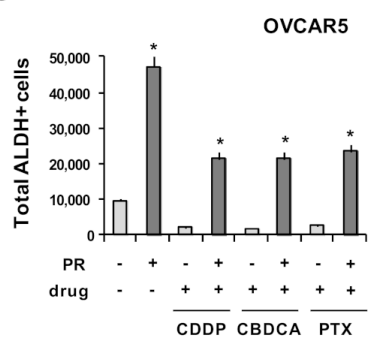

E

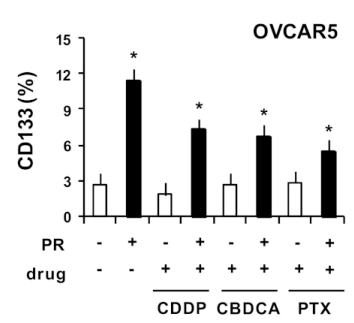

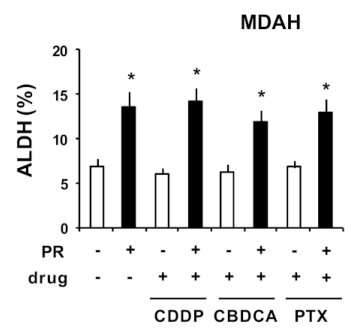

D

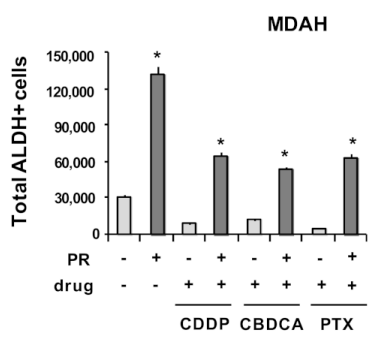

$\mathbf{F}$

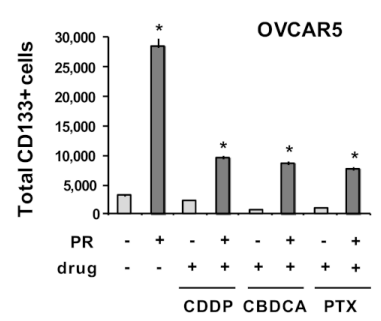

Figure 6. PR increased ALDH- and CD133-positive cells after drug treatment. OVCAR5 and MDAH cells were cultured for 5 days with PR $(10 \%)$ in non-adherent conditions to form spheroids. Then cells were treated with CDDP, CBDCA and PTX for an additional 3 days. Treated cells were dissociated into single-cell suspensions by means of trypsinization. Histograms show the percentage of ALDH positive cells in OVCAR5 (A) and MDAH (B). Number of OVCAR5 (C) and MDAH (D) ALDHpositive cells. Histograms showing the percentage (E) and the number (F) of OVCAR5 CD133-positive cells. Data are expressed as mean \pm SD of three replicates with three different PR pools and represent the percentage with respect to the control medium. ${ }^{*} p<0.01$ (untreated vs. PR treated cells).

The percentage of CD133+ cells increased in the presence of PR, but was reduced after drug treatment (Figure 6E); nevertheless, the total number of CD133+ cells remained significantly higher with respect to OvCa cells without PR (Figure 6F). In line with preclinical and clinical studies demonstrating that in cancer patients and mouse models of OvCa high platelet counts were related to a poor responses to chemotherapy (platinating 
agents and taxanes) [5,44], our results suggest that platelet products, by promoting the expansion of CD133 and especially ALDH+ cells (the putative OvCa-CSCs), could promote their survival during chemotherapy.

PR contains several growth factors that have been involved in OvCa progression, including CSCs expansion and drug resistance (Supplemental Table S2) -EGF, secreted by M2-like TAMs, activates the EGFR-ERK signaling pathway and promotes the progression of OvCa $[45,46]$; EGFR blockade targets ALDH-CSCs and reverses cisplatin resistance [47-49]; anti-IGF-1R-targeted strategies potentiate the efficacy of platinum-based chemotherapy [50,51]; PDGF, secreted by mesenchymal stromal cells (MSCs), induces platinum resistance and CSC enrichment (CD133, and ALDH in OvCa heterospheroids) [52]; TGF $\beta$ increases OvCa growth $[18,22,53]$ and its neutralization potentiates tumor immunity and decreases OvCa progression [54,55]; CCL5 and CCR5 are mainly expressed by CD133+ OvCa stem-like cells [56], CCL2/CCL5, secreted by stromal cells, induces IL-6/PYK2dependent chemoresistance in OvCa cells [57] and cisplatin, by inducing the secretion of CCL5 by cancer-associated fibroblasts (CAFs), promotes cisplatin resistance [16]. Thus, the interaction of OvCa cells with platelets [20] and their products may contribute to the expansion of ovarian CSCs, as well as to decreased drug activity and consequently to tumor progression [58].

\section{Materials and Methods}

\subsection{Drugs}

Cisplatin (CDDP), purchased from Mayne Pharma (Naples, Italy), carboplatin (CBDCA) from Teva Pharmaceutical Industries (Milan, Italy, S.r.l), and Paclitaxel (PTX, TAXOL ${ }^{\circledR}$ ) from Accord Healthcare Italia (Milan, Italy) were surplus drugs from the clinical pharmacy of CRO Aviano.

\subsection{Platelet-Releasate (PR) Production and Cytokine Evaluation}

Pools of PR were obtained as previously described [27]. Briefly, leukocyte-depleted PR was obtained by plasma platelet apheresis from healthy donors. Platelet activation was performed in $\mathrm{PR}$ via the addition of $\mathrm{CaCl}_{2}$. Three separate samples were pooled together to obtain 3 different pools that were used to perform experiments. Concentrations of PDGFAA, PDGF-AB, PDGF-BB, TGF- $\beta$, FGF, EGF, IGF-1, VEGF and CCL5 were measured in the 3 different pools (Supplemental Table S1), using commercially available Quantikine ELISA kits (R\&D Systems, Minneapolis, MN, USA) according to the manufacturer's instructions.

\subsection{Cell Lines and Culture Conditions}

The A2780 cell line (endometrioid adenocarcinoma) was from Sigma (Inc., St. Louis, MO, USA); MDAH-2774 (CRL-10303) (high grade endometrioid-carcinomas) was from ATCC. Dr. Baldassarre (CRO, Aviano, Italy) provided OVCAR5 and OVCAR8 (high grade ovarian serous adenocarcinoma) cells. All cell lines were routinely tested for mycoplasma, with negative results, and authenticated in our laboratory using a PowerPlex 16 HS System (Promega, Madison, WI, USA) and GeneMapper ID version 3.2.1 to identify DNA short tandem repeats. Cells were cultured in AQ MEDIA-RPMI-1640 (R2405, Sigma-AldrichItaly) supplemented with $10 \%$ heat-inactivated fetal bovine serum (FBS, F2442FBS; Sigma), $0.2 \mathrm{mg} / \mathrm{mL}$ penicillin/streptomycin (P4333, Sigma) and $0.1 \%(w / v)$ L-glutamine (Sigma) at $37^{\circ} \mathrm{C}$ in a $5 \% \mathrm{CO}_{2}$ fully humidified atmosphere.

\subsection{Spheroid Formation, Growth and Treatment}

To generate spheroids, cells were cultured under non-adherent conditions in 12well plates coated twice with $20 \mathrm{mg} / \mathrm{mL}$ of poly(2-hydroxyethyl methacrylate) (polyHEMA; Sigma, P3932) in 95\% ethanol and washed once with PBS before cell seeding. Cells $\left(10 \times 10^{3} / \mathrm{mL}\right)$ were cultured in RPMI medium plus $1 \%$ FCS and treated with increasing concentrations of PR pools (2.5\%, $5 \%$ and $10 \%)$. After 5 days, spheroids were counted and captured using an inverted microscope (Eclipse TS/100, Nikon) with a DS Camera Control 
Unit DS-L2 photomicrographic system. To evaluate drugs' effects, spheroids were treated with CDDP, CBDCA and PTX for 3 additional days. Then, spheroids were dissociated into single-cell suspensions by trypsinization for further analysis [25]. The half maximal inhibitory concentrations $\left(\mathrm{IC}_{50}\right)$ for each drug, previously calculated in OvCa cell layers, are shown in Supplemental Table S2. Drug activity was also evaluated on preformed single spheroids, as previously described [26]. Briefly, OVCAR8 cells (500 cells/well) were seeded in a 96-well round-bottom plate coated with poly-HEMA (Sigma) to generate single spheroids with a defined size. After 3 days, OVCAR8 spheroids were treated with increasing concentrations of PR for 24 hours, then for an additional 3 days with CDDP, CBDCA and PTX. Drug activity was evaluated through the measurement of spheroid size [26] using an inverted microscope (Eclipse TS/100, Nikon) and spheroids' volumes were calculated using the formula width ${ }^{2} \times$ length $\left.\times 3.14\right) / 6$ [59].

\subsection{Flow Cytometry}

Spheroids were dissociated into single-cell suspensions by means of trypsinization. Then, Annexin-V-FITC (556419, Becton Dickinson Pharmingen, Milano, Italy) binding, CD133 expression (AC133-PE, 130-080-801, Miltenyi Biotec S.r.l. Bologna, Italy) and aldehyde dehydrogenase (ALDH) enzymatic activity (Aldeflour, 01700) (Stem Cell Technologies, Inc., Cambridge, MA, USA) were evaluated as previously described [25]. Viable ALDH+ labeled cells were identified according to their forward and right-angle scattering, electronically gated and analyzed on a FACSCalibur flow cytometer (BD), using CellQuest Software (BD). The total number of ALDH+ cells was calculated by multiplying the percentage of ALDH-positive cells by the recovered OvCa cells after drug and PR treatment. TGFß1-blocking antibody (TB21) (GTX21279) (GeneTex Inc.) (Prodotti Gianni, Milano, Italy) was used.

\subsection{Statistics}

Statistical analysis was performed using GraphPad Prism 6 Software (GraphPad). The significance of differences was determined by Student's $t$-test for comparisons between two groups. Analysis of variance was used to evaluate the correlation of data among three or more groups; consecutive multiple comparison analysis was performed using Dunnett tests. ${ }^{*} p<0.05$ was considered statistically significant.

\section{Conclusions}

Platelets and their products, by maintaining high levels of CSCs during drug treatment and favoring the expansion of drug resistant clones, may determine the failure of therapy and even induce relapse with a drug-resistant disease and may be considered new actors in tumor progression, mediated by the tumor microenvironment. In this context, targeting platelets with anti-platelet drugs [21], such as aspirin [60], or receptors activated by plateletsecreted growth factors [47] may expand the therapeutic tools available to improve standard chemotherapy. Finally, PR may help to define the molecules involved in CSC expansion and drug resistance and to find new therapeutic targets in OvCa.

\section{Authors Contributions}

Conceptualization, methodology and validation, N.C., C.B. and D.A.; investigation, formal analysis, N.C., C.B., C.D. and F.A.; data curation, N.C., C.B. and F.A.; writingoriginal draft preparation D.A.; writing-review and editing, D.A., N.C., A.C. and M.M.; supervision, D.A.; funding acquisition D.A. and M.M. All authors have read and agreed to the published version of the manuscript.

Supplementary Materials: The following are available online at https: / / www.mdpi.com/1422-0 067/22/6/3019/s1. Table S1: Concentrations of growth factors in platelet releasate; Table S2: Halfmaximal inhibitory concentrations (IC50) of carboplatin (CDBCA), cisplatin (CDDP) and paclitaxel (PTX) in ovarian cancer cell lines OVCAR5, OVCAR8 and MDAH; Figure S1: Anti-TGF $\beta$ inhibited the increase of ALDH activity and CD133 expression by PR in OvCa cells. 
Funding: This work was supported in part by grant IG 15844 from the Italian Association for Cancer Research (D.A.), by the Italian Ministry of Health (Ricerca Corrente) (Institutional Grant, no grant number provided), by a CRO Intramural grant (code J32F16001310007) (M.M.), by the association "Finchè ci siete voi ci sono anch'io" (code J31I17000440007) (M.M.), by "Alleanza Contro il Cancro (ACC)" (code J34I20000600001)(M.M.) and by "Associazione Italiana contro le Leucemie-linfomi e mieloma ONLUS (AIL)"(M.M.).

Institutional Review Board Statement: Not applicable.

Informed Consent Statement: Not applicable.

Data Availability Statement: Data is contained within the article or Supplementary Material.

Conflicts of Interest: The authors declare no conflict of interest.

\section{References}

1. Belluco, C.; Forlin, M.; DelRio, P.; Rega, D.; Degiuli, M.; Sofia, S.; Olivieri, M.; Pucciarelli, S.; Zuin, M.; De Manzoni, G.; et al. Elevated platelet count is a negative predictive and prognostic marker in locally advanced rectal cancer undergoing neoadjuvant chemoradiation: A retrospective multi-institutional study on 965 patients. BMC Cancer 2018, 18, 1094. [CrossRef]

2. Liu, S.; Fang, J.; Jiao, D.; Liu, Z. Elevated Platelet Count Predicts Poor Prognosis in Breast Cancer Patients with Supraclavicular Lymph Node Metastasis. Cancer Manag. Res. 2020, 12, 6069-6075. [CrossRef]

3. Catani, M.V.; Savini, I.; Tullio, V.; Gasperi, V. The "Janus Face" of Platelets in Cancer. Int. J. Mol. Sci. 2020, 21, 788. [CrossRef]

4. Stone, R.L.; Nick, A.M.; McNeish, I.A.; Balkwill, F.; Han, H.D.; Bottsford-Miller, J.; Rupairmoole, R.; Armaiz-Pena, G.N.; Pecot, C.V.; Coward, J.; et al. Paraneoplastic Thrombocytosis in Ovarian Cancer. N. Engl. J. Med. 2012, 366, 610-618. [CrossRef] [PubMed]

5. Bottsford-Miller, J.; Choi, H.-J.; Dalton, H.J.; Stone, R.L.; Cho, M.S.; Haemmerle, M.; Nick, A.M.; Pradeep, S.; Zand, B.; Previs, R.A.; et al. Differential Platelet Levels Affect Response to Taxane-Based Therapy in Ovarian Cancer. Clin. Cancer Res. 2015, 21, 602-610. [CrossRef] [PubMed]

6. Hufnagel, D.H.; Cozzi, G.D.; Crispens, M.A.; Beeghly-Fadiel, A. Platelets, Thrombocytosis, and Ovarian Cancer Prognosis: Surveying the Landscape of the Literature. Int. J. Mol. Sci. 2020, 21, 8169. [CrossRef] [PubMed]

7. Hu, Q.; Hada, A.; Han, L. Platelet count as a biomarker for monitoring treatment response and disease recurrence in recurrent epithelial ovarian cancer. J. Ovarian Res. 2020, 13, 1-11. [CrossRef] [PubMed]

8. Schlesinger, M. Role of platelets and platelet receptors in cancer metastasis. J. Hematol. Oncol. 2018, 11, 1-15. [CrossRef] [PubMed]

9. Lucotti, S.; Muschel, R.J. Platelets and Metastasis: New Implications of an Old Interplay. Front. Oncol. 2020, 10, 1350. [CrossRef]

10. Elaskalani, O.; Berndt, M.C.; Falasca, M.; Metharom, P. Targeting Platelets for the Treatment of Cancer. Cancers 2017, 9, 94. [CrossRef]

11. Huong, P.T.; Nguyen, L.T.; Nguyen, X.-B.; Lee, S.K.; Bach, D.-H. The Role of Platelets in the Tumor-Microenvironment and the Drug Resistance of Cancer Cells. Cancers 2019, 11, 240. [CrossRef]

12. Franco, A.T.; Ware, J. Pathophysiology 2: The Role of Platelets in Cancer Biology. Cancer Treat. Res. 2019, 179, 37-54. [CrossRef]

13. Johnson, K.E.; Ceglowski, J.R.; Roweth, H.G.; Forward, J.A.; Tippy, M.D.; El-Husayni, S.; Kulenthirarajan, R.; Malloy, M.W.; Machlus, K.R.; Chen, W.Y.; et al. Aspirin inhibits platelets from reprogramming breast tumor cells and promoting metastasis. Blood Adv. 2019, 3, 198-211. [CrossRef]

14. Gianazza, E.; Brioschi, M.; Baetta, R.; Mallia, A.; Banfi, C.; Tremoli, E. Platelets in Healthy and Disease States: From Biomarkers Discovery to Drug Targets Identification by Proteomics. Int. J. Mol. Sci. 2020, 21, 4541. [CrossRef] [PubMed]

15. Aldinucci, D.; Borghese, C.; Casagrande, N. The CCL5/CCR5 Axis in Cancer Progression. Cancers 2020, 12, 1765. [CrossRef] [PubMed]

16. Zhou, B.; Sun, C.; Li, N.; Shan, W.; Lu, H.; Guo, L.; Guo, E.; Xia, M.; Weng, D.; Meng, L.; et al. Cisplatin-induced CCL5 secretion from CAFs promotes cisplatin-resistance in ovarian cancer via regulation of the STAT3 and PI3K/Akt signaling pathways. Int. J. Oncol. 2016, 48, 2087-2097. [CrossRef]

17. Pokhriyal, R.; Hariprasad, R.; Kumar, L.; Hariprasad, G. Chemotherapy Resistance in Advanced Ovarian Cancer Patients. Biomark. Cancer 2019, 11, 11. [CrossRef]

18. Hu, Q.; Hisamatsu, T.; Haemmerle, M.; Cho, M.S.; Pradeep, S.; Rupaimoole, R.; Rodriguez-Aguayo, C.; Lopez-Berestein, G.; Wong, S.T.; Sood, A.K.; et al. Role of Platelet-Derived Tgf $\beta 1$ in the Progression of Ovarian Cancer. Clin. Cancer Res. 2017, 23, 5611-5621. [CrossRef] [PubMed]

19. Yuan, L.; Liu, X. Platelets are associated with xenograft tumor growth and the clinical malignancy of ovarian cancer through an angiogenesis-dependent mechanism. Mol. Med. Rep. 2015, 11, 2449-2458. [CrossRef]

20. Orellana, R.; Kato, S.; Erices, R.; Bravo, M.L.; Gonzalez, P.; Oliva, B.; Cubillos, S.; Valdivia, A.; Ibañez, C.; Brañes, J.; et al. Platelets enhance tissue factor protein and metastasis initiating cell markers, and act as chemoattractants increasing the migration of ovarian cancer cells. BMC Cancer 2015, 15, 1-16. [CrossRef]

21. Cooke, N.M.; Spillane, C.D.; Sheils, O.; O'Leary, J.; Kenny, D. Aspirin and P2Y12 inhibition attenuate platelet-induced ovarian cancer cell invasion. BMC Cancer 2015, 15, 1-10. [CrossRef] [PubMed] 
22. Cho, M.S.; Bottsford-Miller, J.; Vasquez, H.G.; Stone, R.; Zand, B.; Kroll, M.H.; Sood, A.K.; Afshar-Kharghan, V. Platelets increase the proliferation of ovarian cancer cells. Blood 2012, 120, 4869-4872. [CrossRef]

23. Cortez, A.J.; Tudrej, P.; Kujawa, K.A.; Lisowska, K.M. Advances in ovarian cancer therapy. Cancer Chemother. Pharmacol. 2018, 81, 17-38. [CrossRef] [PubMed]

24. Nunes, A.S.; Barros, A.S.; Costa, E.C.; Moreira, A.F.; Correia, I.J. 3D tumor spheroids as in vitro models to mimic in vivo human solid tumors resistance to therapeutic drugs. Biotechnol. Bioeng. 2019, 116, 206-226. [CrossRef]

25. Casagrande, N.; Celegato, M.; Borghese, C.; Mongiat, M.; Colombatti, A.; Aldinucci, D. Preclinical Activity of the Liposomal Cisplatin Lipoplatin in Ovarian Cancer. Clin. Cancer Res. 2014, 20, 5496-5506. [CrossRef] [PubMed]

26. Borghese, C.; Casagrande, N.; Corona, G.; Aldinucci, D. Adipose-Derived Stem Cells Primed with Paclitaxel Inhibit Ovarian Cancer Spheroid Growth and Overcome Paclitaxel Resistance. Pharmaceutics 2020, 12, 401. [CrossRef]

27. Durante, C.; Agostini, F.; Abbruzzese, L.; Toffola, R.T.; Zanolin, S.; Suine, C.; Mazzucato, M. Growth factor release from platelet concentrates: Analytic quantification and characterization for clinical applications. Vox Sang. 2013, 105, 129-136. [CrossRef]

28. Borghese, C.; Agostini, F.; Durante, C.; Colombatti, A.; Mazzucato, M.; Aldinucci, N. Clinical-grade quality platelet-rich plasma releasate (PRP-R/SRGF) from $\mathrm{CaCl} 2$-activated platelet concentrates promoted expansion of mesenchymal stromal cells. Vox Sang. 2016, 111, 197-205. [CrossRef] [PubMed]

29. Agostini, F.; Vicinanza, C.; Di Cintio, F.; Battiston, M.; Lombardi, E.; Golinelli, G.; Durante, C.; Toffoli, G.; Dominici, M.; Mazzucato, M. Adipose mesenchymal stromal/stem cells expanded by a GMP compatible protocol displayed improved adhesion on cancer cells in flow conditions. Ann. Transl. Med. 2020, 8, 533. [CrossRef]

30. Ford, C.E.; Werner, B.; Hacker, N.F.; Warton, K. The untapped potential of ascites in ovarian cancer research and treatment. Br. J. Cancer 2020, 123, 9-16. [CrossRef]

31. Lee, J.M.; Mhawech-Fauceglia, P.; Lee, N.; Parsanian, L.C.; Lin, Y.G.; Gayther, S.A.; Lawrenson, K. A three-dimensional microenvironment alters protein expression and chemosensitivity of epithelial ovarian cancer cells in vitro. Lab. Investig. 2013, 93, 528-542. [CrossRef]

32. Liao, J.; Qian, F.; Tchabo, N.; Mhawech-Fauceglia, P.; Beck, A.; Qian, Z.; Wang, X.; Huss, W.J.; Lele, S.B.; Morrison, C.D.; et al. Ovarian Cancer Spheroid Cells with Stem Cell-Like Properties Contribute to Tumor Generation, Metastasis and Chemotherapy Resistance through Hypoxia-Resistant Metabolism. PLoS ONE 2014, 9, e84941. [CrossRef] [PubMed]

33. Mori, Y.; Yamawaki, K.; Ishiguro, T.; Yoshihara, K.; Ueda, H.; Sato, A.; Ohata, H.; Yoshida, Y.; Minamino, T.; Okamoto, K.; et al. ALDH-Dependent Glycolytic Activation Mediates Stemness and Paclitaxel Resistance in Patient-Derived Spheroid Models of Uterine Endometrial Cancer. Stem Cell Rep. 2019, 13, 730-746. [CrossRef] [PubMed]

34. Pieterse, Z.; Amaya-Padilla, M.A.; Singomat, T.; Binju, M.; Madjid, B.D.; Yu, Y.; Kaur, P. Ovarian cancer stem cells and their role in drug resistance. Int. J. Biochem. Cell Biol. 2019, 106, 117-126. [CrossRef] [PubMed]

35. Terraneo, N.; Jacob, F.; Dubrovska, A.; Grünberg, J. Novel Therapeutic Strategies for Ovarian Cancer Stem Cells. Front. Oncol. 2020, 10, 319. [CrossRef] [PubMed]

36. Singh, T.; Neal, A.S.; Moatamed, N.A.; Memarzadeh, S. Exploring the Potential of Drug Response Assays for Precision Medicine in Ovarian Cancer. Int. J. Mol. Sci. 2020, 22, 305. [CrossRef] [PubMed]

37. Kuroki, L.; Guntupalli, S.R. Treatment of epithelial ovarian cancer. BMJ 2020, 371, m3773. [CrossRef]

38. Vassalli, G. Aldehyde Dehydrogenases: Not Just Markers, but Functional Regulators of Stem Cells. Stem Cells Int. 2019, 2019 , 1-15. [CrossRef] [PubMed]

39. Chefetz, I.; Grimley, E.; Yang, K.; Hong, L.; Vinogradova, E.V.; Suciu, R.; Kovalenko, I.; Karnak, D.; Morgan, C.A.; Chtcherbinine, M.; et al A Pan-ALDH1A Inhibitor Induces Necroptosis in Ovarian Cancer Stem-like Cells. Cell Rep. 2019, 26, 3061-3075.e6. [CrossRef] [PubMed]

40. Liu, C.L.; Chen, Y.J.; Fan, M.H.; Liao, Y.J.; Mao, T.L. Characteristics of CD133-Sustained Chemoresistant Cancer Stem-Like Cells in Human Ovarian Carcinoma. Int. J. Mol. Sci. 2020, 21, 6467. [CrossRef]

41. Kryczek, I.; Liu, S.; Roh, M.; Vatan, L.; Szeliga, W.; Wei, S.; Banerjee, M.; Mao, Y.; Kotarski, J.; Wicha, M.S.; et al. Expression of aldehyde dehydrogenase and CD133 defines ovarian cancer stem cells. Int. J. Cancer 2011, 130, 29-39. [CrossRef] [PubMed]

42. Silva, I.A.; Bai, S.; McLean, K.; Yang, K.; A Griffith, K.; Thomas, D.; Ginestier, C.; Johnston, C.; Kueck, A.; Reynolds, R.K.; et al. Aldehyde Dehydrogenase in Combination with CD133 Defines Angiogenic Ovarian Cancer Stem Cells That Portend Poor Patient Survival. Cancer Res. 2011, 71, 3991-4001. [CrossRef] [PubMed]

43. Muralikrishnan, V.; Hurley, T.D.; Nephew, K.P. Targeting Aldehyde Dehydrogenases to Eliminate Cancer Stem Cells in Gynecologic Malignancies. Cancers 2020, 12, 961. [CrossRef] [PubMed]

44. Haemmerle, M.; Stone, R.L.; Menter, D.G.; Afshar-Kharghan, V.; Sood, A.K. The Platelet Lifeline to Cancer: Challenges and Opportunities. Cancer Cell 2018, 33, 965-983. [CrossRef]

45. Zeineldin, R.; Muller, C.Y.; Stack, M.S.; Hudson, L.G. Targeting the EGF Receptor for Ovarian Cancer Therapy. J. Oncol. 2009, 2010, 1-11. [CrossRef] [PubMed]

46. Zeng, X.-Y.; Xie, H.; Yuan, J.; Jiang, X.-Y.; Yong, J.-H.; Zeng, D.; Dou, Y.-Y.; Xiao, S.-S. M2-like tumor-associated macrophagessecreted EGF promotes epithelial ovarian cancer metastasis via activating EGFR-ERK signaling and suppressing lncRNA LIMT expression. Cancer Biol. Ther. 2019, 20, 956-966. [CrossRef] [PubMed] 
47. Kaipio, K.; Chen, P.; Roering, P.; Huhtinen, K.; Mikkonen, P.; Östling, P.; Lehtinen, L.; Mansuri, N.; Korpela, T.; Potdar, S.; et al. ALDH1A1-related stemness in high-grade serous ovarian cancer is a negative prognostic indicator but potentially targetable by EGFR/mTOR-PI3K/aurora kinase inhibitors. J. Pathol. 2020, 250, 159-169. [CrossRef] [PubMed]

48. Granados, M.L.; Hudson, L.G.; Samudio-Ruiz, S.L. Contributions of the Epidermal Growth Factor Receptor to Acquisition of Platinum Resistance in Ovarian Cancer Cells. PLoS ONE 2015, 10, e0136893. [CrossRef]

49. Poursheikhani, A.; Yousefi, H.; Tavakoli-Bazzaz, J.; Ghaffari, S.H. EGFR Blockade Reverses Cisplatin Resistance in Human Epithelial Ovarian Cancer Cells. Iran. Biomed. J. 2020, 24, 365-373. [CrossRef]

50. Liefers-Visser, J.; Meijering, R.; Reyners, A.; Van Der Zee, A.; De Jong, S. IGF system targeted therapy: Therapeutic opportunities for ovarian cancer. Cancer Treat. Rev. 2017, 60, 90-99. [CrossRef]

51. Camblin, A.J.; Tan, G.; Curley, M.D.; Yannatos, I.; Iadevaia, S.; Rimkunas, V.; Mino-Kenudson, M.; Bloom, T.; Schoeberl, B.; Drummond, D.C.; et al. Dual targeting of IGF-1R and ErbB3 as a potential therapeutic regimen for ovarian cancer. Sci. Rep. 2019, 9, 1-10. [CrossRef] [PubMed]

52. Raghavan, S.; Snyder, C.S.; Wang, A.; McLean, K.; Zamarin, D.; Buckanovich, R.J.; Mehta, G. Carcinoma-Associated Mesenchymal Stem Cells Promote Chemoresistance in Ovarian Cancer Stem Cells via PDGF Signaling. Cancers 2020, 12, 2063. [CrossRef]

53. Alsina-Sanchís, E.; Figueras, A.; Lahiguera, A.; Gil-Martín, M.; Pardo, B.; Piulats, J.M.; Martí, L.; Ponce, J.; Matias-Guiu, X.; Vidal, A.; et al. TGF $\beta$ Controls Ovarian Cancer Cell Proliferation. Int. J. Mol. Sci. 2017, 18, 1658. [CrossRef] [PubMed]

54. Roane, B.M.; Arend, R.C.; Birrer, M.J. Review: Targeting the Transforming Growth Factor-Beta Pathway in Ovarian Cancer. Cancers 2019, 11, 668. [CrossRef]

55. Roane, B.M.; Meza-Perez, S.; Katre, A.A.; Goldsberry, W.N.; Randall, T.D.; Norian, L.A.; Birrer, M.J.; Arend, R.C. Neutralization of TGF $\beta$ Improves Tumor Immunity and Reduces Tumor Progression in Ovarian Carcinoma. Mol. Cancer Ther. 2021, $20,602-611$. [CrossRef] [PubMed]

56. Long, H.; Xie, R.; Xiang, T.; Zhao, Z.; Lin, S.; Liang, Z.; Chen, Z.; Zhu, B. Autocrine CCL5 Signaling Promotes Invasion and Migration of CD133+Ovarian Cancer Stem-Like Cells via NF-kB-Mediated MMP-9 Upregulation. STEM CELLS 2012, 30, 2309-2319. [CrossRef]

57. Pasquier, J.; Gosset, M.; Geyl, C.; Hoarau-Véchot, J.; Chevrot, A.; Pocard, M.; Mirshahi, M.; Lis, R.; Rafii, A.; Touboul, C. CCL2/CCL5 secreted by the stroma induce IL-6/PYK2 dependent chemoresistance in ovarian cancer. Mol. Cancer 2018, $17,1-14$. [CrossRef] [PubMed]

58. Varas-Godoy, M.; Rice, G.; Illanes, S.E. The Crosstalk between Ovarian Cancer Stem Cell Niche and the Tumor Microenvironment. Stem Cells Int. 2017, 2017, 1-8. [CrossRef]

59. Dolznig, H.; Rupp, C.; Puri, C.; Haslinger, C.; Schweifer, N.; Wieser, E.; Kerjaschki, D.; Garin-Chesa, P. Modeling colon adenocarcinomas in vitro a $3 \mathrm{D}$ co-culture system induces cancer-relevant pathways upon tumor cell and stromal fibroblast interaction. Am. J. Pathol. 2011, 179, 487-501. [CrossRef] [PubMed]

60. Joharatnam-Hogan, N.; Cafferty, F.H.; Macnair, A.; Ring, A.; E Langley, R. The role of aspirin in the prevention of ovarian, endometrial and cervical cancers. Women's Health 2020, 16, 1745506520961710. [CrossRef] 